\title{
Menstrual Cycle Phase and Sexual Arousability in Women
}

\author{
A. K. Slob, Ph.D., ${ }^{1,2}$ M. Ernste, M.D., ${ }^{1}$ and J. J. van der Werff ten \\ Bosch, M.D., Ph.D. ${ }^{1}$
}

\begin{abstract}
Sexual arousability of women has not been consistently found to vary significantly over phases of the menstrual cycle. We studied changes in the temperature of a labium minus and subjective sexual and genital arousal recorded on semantic scales while watching erotic video in 12 women with natural menstrual cycles and 12 women using low-dose estrogen oral contraceptive pills. Natural cycle phase was ascertained by blood progesterone. Subjects were tested twice, with an interval of about 2 weeks. Half of each group had their first test during their luteal phase, the others during their follicular phase. Women tested for the first time in their follicular phase were sexually more aroused than women tested for the first time during their luteal phase. This was true for both objective (i.e., a labium minus change in temperature) and subjective genital arousal. When these women were retested in their alternative phase of the menstrual cycle, those who were then follicular did not score higher than those who were then luteal. On the contrary, the latter group scored as high as when tested during their follicular phase. This phenomenon was observed both in women with and without oral contraception. The nature of the menstrual phase (i.e., natural or pill-induced) seems irrelevant in this respect. Sexual arousal achieved during the first session appeared to be correlated with an increase in desire for making love during the rest of the day and night. Only 1 of 12 women tested during their luteal phase indicated an increase in desire to make love, while 6 of 12 women tested during their follicular phase indicated an increase. Apparently the menstrual cycle phase during the first test determines the immediate response and indirectly affects the response during the second test approximately 10 days later. In a

${ }^{1}$ Department of Endocrinology \& Reproduction, Faculty of Medicine and Health Sciences, Erasmus University, P. O. Box 1738, 3000 DR Rotterdam, The Netherlands.

${ }^{2}$ To whom correspondence should be addressed.
\end{abstract}


random block design the difference in sexual response between follicular and luteal phase of the menstrual cycle disappears.

KEY WORDS: menstrual cycle; sexual arousal; oral contraception; psychophysiology; labium minus temperature.

\section{INTRODUCTION}

In lower mammals there is a strict time relationship between ovarian cycle and sexual behavior such that virtually all sexual activity takes place around the time of ovulation, i.e., the time of maximal fertility (e.g., Beach, 1948; Leshner, 1978). In nonhuman primates this relationship is less distinct but nevertheless sexual activity is highest during the late follicular and periovulatory period of the menstrual cycle (e.g., Nieuwenhuijsen et al., 1986). In the human, no unequivocal association has been found between female sexuality and the menstrual cycle (e.g., Bancroft, 1989; Morris and Udry, 1982). As Bancroft pointed out, "evidence of the distribution of sexual activity and sexual interest during the menstrual cycle of women is conflicting, though the majority fails to support a mid-cycle or periovulatory peak" (p. 108).

Major obstacles in such studies on women are the precise assessment of the cycle phase and the assessment of the intrinsic sexual state of the female. The term "sexual state" is used to include the degree of feeling sexual and the urge to seek sexual arousal. In recent years attempts have been made to develop methods to measure objectively and subjectively the sexual state of women in relation to their menstrual cycle (Hoon et al., 1982; Morrell et al., 1984; Schreiner-Engel et al., 1981). Again, results have been conflicting, possibly through methodological snags. The prevailing method of objective assessment of sexual arousal is vaginal photoplethysmography, which yields data that can be difficult to interpret (Hatch, 1979).

We employed the method described by Henson et al. (1982) which involves the measurement of changes in the temperature of a labium minus while watching erotic video. The study comprised women with natural menstrual cycles and women who were using low-dose estrogen oral contraceptive pills. All women were tested during midfollicular and midluteal phase of their menstrual cycles. The precise assessment of the menstrual cycle phase was carried out by blood progesterone levels. 


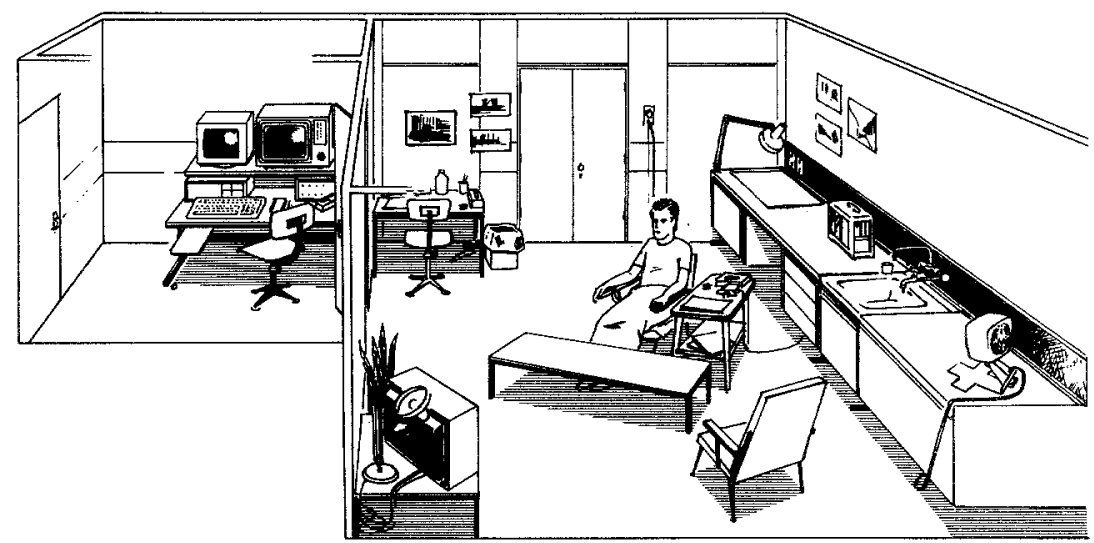

Fig. 1. Experimental room and antechamber used for psychophysiological research (drawn by C. de Vries, Audiovisual Center, Erasmus University Rotterdam). Reprinted from Slob et al., 1990, J. Sex Marital Ther. 16: 59-69.

\section{MATERIAL AND METHOD}

\section{Subjects}

Recruitment took place through advertisement, which indicated the nature of the study and offered a fee of Dfl 40 (about U.S. \$20). Selection was made with the following criteria: age between 18 and 50 years; heterosexual orientation; not pregnant or lactating. Twenty-four women were selected so that 12 were on oral contraception (OC) and 12 were not. Procedures of the investigation were fully explained and all subjects gave informed consent. The women were invited to visit the laboratory twice, once on approximately Day 9 of the menstrual cycle and again on about Day 20. Half of the subjects of each group (with or without oral contraception) first visited the lab on Day 9, the others first visited on Day 20.

\section{Experimental Setting}

The experimental setting has been described before (Slob et al., 1990). The experiment was carried out in a testing room (mean temperature of $26^{\circ} \mathrm{C}$ ), connected to an antechamber. The subject was seated in a comfortable chair. In the antechamber the female investigator (M.E.) was able to monitor labial temperature and to control presentation of the stimulus 
materials. An intercom connection between the two rooms enabled experimenter and subject to communicate (Fig. 1). The thermistor clip used for measuring labial temperature was similar to the device first described by Henson et al. (1977).

\section{Experimental Procedures}

During the initial interview, which took place in the testing room, the investigator explained the experimental procedure and the subject was instructed how to attach the thermistor clip at the base of the widest portion of the right labium minus. At this time the subject was given a number of questionnaires as described in the following section. She was instructed when to fill in the questionnaires. The investigator left the room briefly to allow the subject to attach the thermistor clip. After checking the correct position of the thermistor clip, the experimenter retired to the antechamber where the prerecording was started. Meanwhile the subject filled in the sexual activity inventory and the moods scale. On completion she signaled the investigator, who started the experimental period of temperature recording as soon as the temperature had reached a stable level. Two minutes later the video films began: 3 min neutral film (Sesame Street) followed by an erotic film. Following the erotic film the subject filled in the sexual arousal and feelings list. Blood was taken by vena puncture for hormone determination (progesterone: de Jong et al., 1974; testosterone: Verjans et al., 1973). The session was closed with a short debriefing.

\section{Questionnaires and Films}

The sexual activity inventory consisted of 42 questions dealing with the quantitative and qualitative aspects of sexual relationship(s) and sexual activities. The moods scale, adapted from Sanders et al. (1983) contained 10 items, 4 positive (cheerful and happy; sociable and friendly; energetic and active; relaxed), 5 negative (depressed and unhappy; irritable; aggressive; fatigued and tired; tense and anxious), and 1 indistinct (changeable), with a $100-\mathrm{mm}$ analog scale for each. The sexual arousal and feelings questionnaire assessed subjective sexual arousal, genital and extragenital physiological responses, and psychological emotional feelings in response to the erotic film.

Sexual arousal was scored on a 7-point semantic scale: no arousal (1), very strong arousal (7), genital arousal was also scored on a 7-point semantic scale: no genital feelings (1), strong tickling sensations (4), orgasm (7). The 
Table I. Some Sociosexual Data of the 24 Women Studied (mean \pm SE)

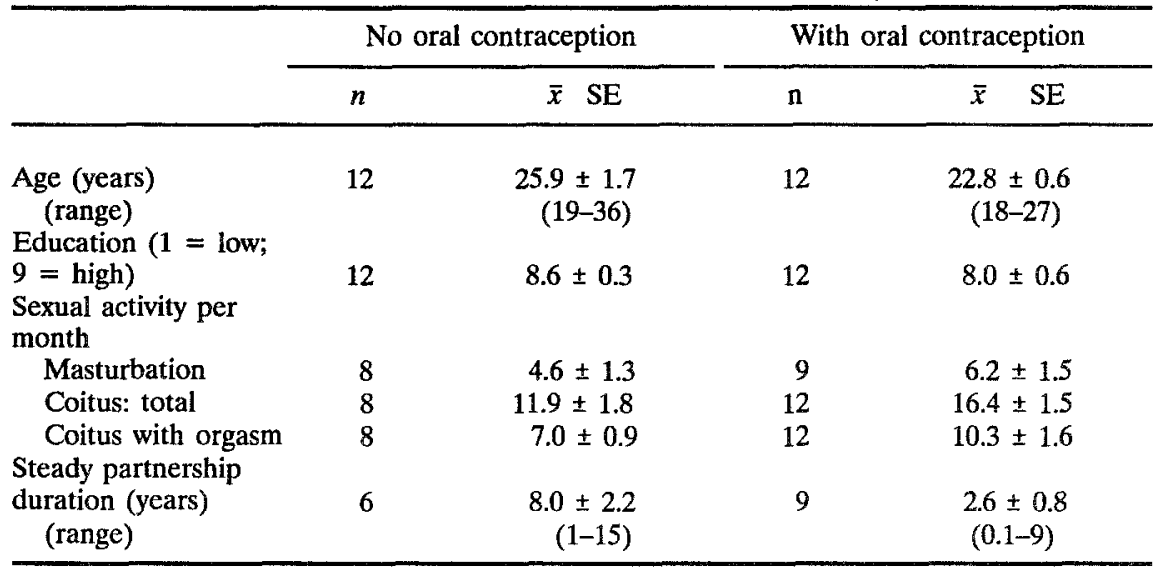

postfilm feelings scale included 10 items, 5 positive (passionate; desire of intercourse; desire of masturbation; horny; voluptuous) and 5 negative (distaste; sad; ashamed; disdainful; angry).

On arrival for the second visit the women were asked to fill in a form with nine questions about their sexual activities during the $24 \mathrm{hr}$ following their first visit.

Two video films were used. Both were fragments of films directed by Candida Royalle. Film A (duration $9 \mathrm{~min}$ ) depicted a man and a women in bed making love in various ways: cunnilingus, fellatio, masturbation, female orgasm. It ended with intravaginal ejaculation and orgasm of the male. Film $B$ (duration $14 \mathrm{~min}$ ) depicted a man and a woman making love in an elevator with a similar repertoire as film $\mathrm{A}$, including the intravaginal ejaculation of the male.

Half of each subgroup of women (follicular or luteal phase) viewed film A during their first visit, and film $B$ during their second visit. For the other half the sequence of films was reversed.

\section{RESULTS}

Some sociosexual data of the women studied are listed in Table I. Differences between the groups were not relevant since the study was concerned with relationships between phases of natural or artificial menstrual cycle and sexual arousability. All women were relatively young and had a high level of 
Table II. Moods and Blood Hormone Levels on Day of Investigation, and Objective and Subjective Psychophysiological Responses While Watching Erotic Video Films (Mean \pm SE)

\begin{tabular}{|c|c|c|c|c|}
\hline & \multicolumn{2}{|c|}{$\begin{array}{l}\text { No oral contraception } \\
\qquad(n=12)\end{array}$} & \multicolumn{2}{|c|}{$\begin{array}{l}\text { With oral contraception } \\
\qquad(n=12)\end{array}$} \\
\hline & Follicular & Luteal & "Follicular" & "Luteal" \\
\hline \multicolumn{5}{|l|}{ Moods (scale 0-100) } \\
\hline Positive & $53.3 \pm 4.2$ & $55.5 \pm 4.4$ & $61.2 \pm 5.7$ & $58.5 \pm 4.9$ \\
\hline Negative & $21.5 \pm 4.4$ & $20.6 \pm 4.3$ & $19.2 \pm 5.1$ & $21.0 \pm 4.2$ \\
\hline \multicolumn{5}{|l|}{ Hormones (nmol/L) } \\
\hline $\begin{array}{l}\text { Progesterone } \\
\text { (range) }\end{array}$ & $\begin{array}{l}1.0 \pm 0.1 \\
(0.8-1.3)\end{array}$ & $\begin{array}{l}34.8 \pm 3.2 \\
(20.5-49.3)\end{array}$ & $\begin{array}{l}1.3 \pm 0.1 \\
(0.9-1.9)\end{array}$ & $\begin{array}{l}1.4 \pm 0.1 \\
(0.9-2.0)\end{array}$ \\
\hline $\begin{array}{l}\text { Testosterone } \\
\text { (range) }\end{array}$ & $\begin{array}{l}1.3 \pm 0.1 \\
(0.5-1.9)\end{array}$ & $\begin{array}{l}1.3 \pm 0.1 \\
(0.5-2.0)\end{array}$ & $\begin{array}{l}1.2 \pm 0.1 \\
(0.4-2.1)\end{array}$ & $\begin{array}{l}1.0 \pm 0.1 \\
(0.4-1.7)\end{array}$ \\
\hline \multicolumn{5}{|l|}{ Labial temperature $\left({ }^{\circ} \mathrm{C}\right)$} \\
\hline Onset erotic film & $35.7 \pm 0.3$ & $36.1 \pm 0.2$ & $36.5 \pm 0.2$ & $36.1 \pm 0.3$ \\
\hline Change during film & $0.60 \pm 0.08$ & $0.59 \pm 0.12$ & $0.88 \pm 0.14$ & $0.88 \pm 0.17$ \\
\hline \multicolumn{5}{|l|}{$\begin{array}{l}\text { Subjective responses } \\
\text { General sexual arousal } \\
(1=\text { none; } 7=\text { very }\end{array}$} \\
\hline strong) & $4.8 \pm 0.4$ & $4.8 \pm 0.3$ & $4.9 \pm 0.5$ & $4.8 \pm 0.3$ \\
\hline $\begin{array}{l}\text { none; } 7=\text { orgasm }) \\
\text { Postfilm feelings }(1= \\
\text { none; } 7=\text { very } \\
\text { strong) }\end{array}$ & $3.8 \pm 0.4$ & $3.8 \pm 0.4$ & $3.8 \pm 0.5$ & $4.2 \pm 0.3$ \\
\hline Positive & $3.3 \pm 0.5$ & $2.7 \pm 0.3$ & $3.7 \pm 0.5$ & $3.7 \pm 0.4$ \\
\hline Negative & $1.5 \pm 0.2$ & $1.6 \pm 0.2$ & $1.2 \pm 0.1$ & $1.3 \pm 0.2$ \\
\hline
\end{tabular}

education. The majority of women were sexually active and many had a steady partnership.

Eleven women used a single-phase low-estrogen (sub $50 \mu \mathrm{g}$ ) pill, one woman took a triphasic low-estrogen pill. There were 8 sexually active women who used no oral contraception; 2 had a sterilized partner, 2 had an IUD, 1 used a diaphragm, and 3 used condoms.

Natural menstrual cycle phase was verified by determination of blood progesterone levels (Table II). The scores for moods on the day of investigation were similar for both phases of the menstrual cycle (Table II). Positive moods prevailed for all women during both phases of the cycle.

Recordings for individual women of labium minus temperature curves are depicted in Fig. 2. Individual responses were variable. In neither group of women was there an obvious difference between follicular and luteal phase in labial temperature response to visual erotic stimulation.

Other data appear in Table II. When the order of testing is not taken into account, there are no significant differences between the two 

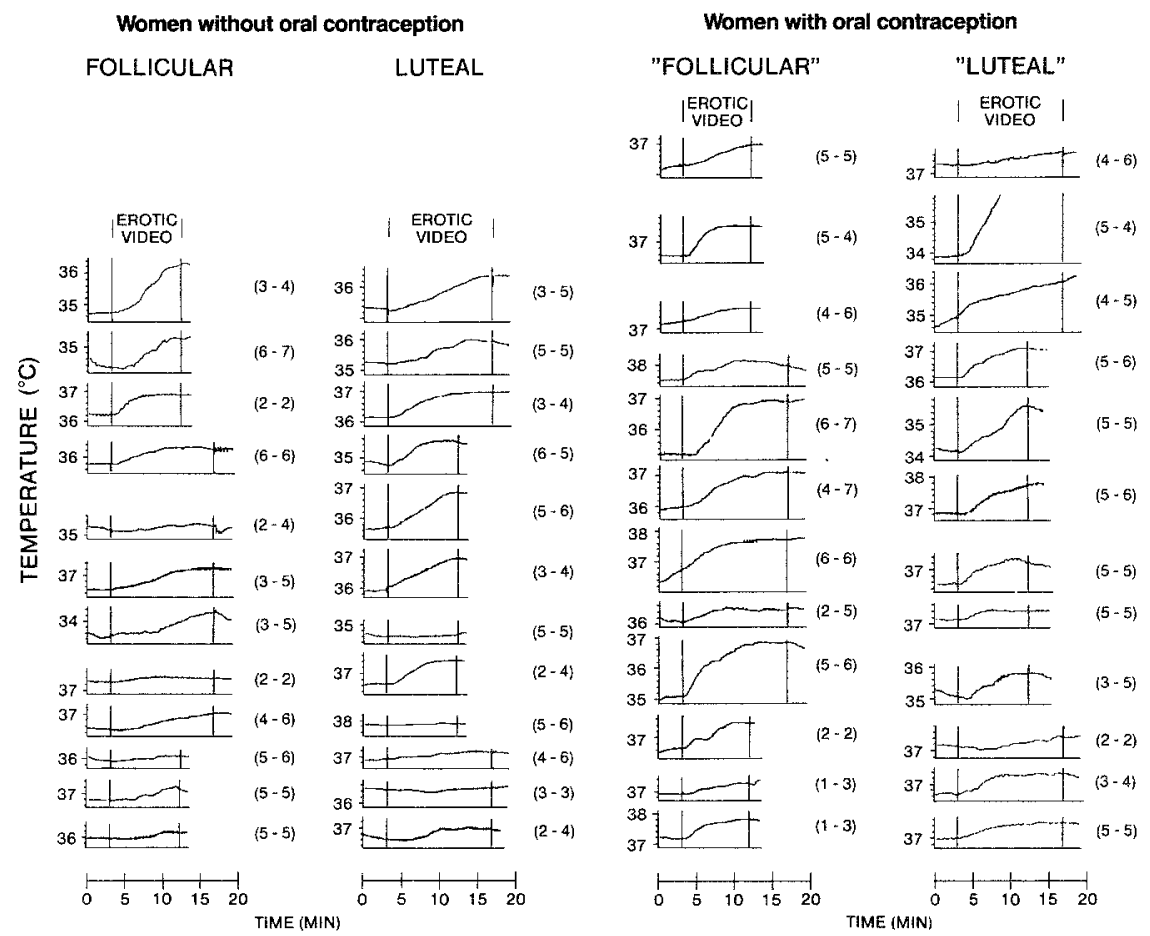

Fig. 2. Individual recordings of labium minus temperature of women without and women with oral contraception during follicular and luteal phase of the menstrual cycle, before (neutral film) and during exposure to an erotic video. Between brackets: the degree of subjective general sexual arousal; the degree of subjective genital arousal. The top six women of each group had their first test during their follicular phase, the bottom half started during their luteal phase.

phases of the cycle for either group of women, for temperatures at the onset of the erotic film, and for the increment during visual erotic stimulation. The same is true for the subjective responses and the postfilm feelings.

Women using OC, compared with women not using OC, have a significantly higher initial labial temperature in the follicular phase ( 36.5 vs. $35.7^{\circ} \mathrm{C}$; Student $\left.t=1.92, p<0.05\right)$ and show a greater increase $(0.88$ vs. $0.60^{\circ} \mathrm{C}$; Student $t=1.80, p<0.05$ ) in labial temperature with erotic video during both the follicular and the luteal phase.

Unexpected findings emerged when data were subjected to a threeway ANOVA with factors oral contraception, phase of the cycle, and order of testing [first test undergone during follicular (Group A) or luteal (Group B) phase]. The main results are shown in Table III. 
Table III. Differences Between Women First Tested During Follicular Phase (Group A) and Women First Tested During Luteal Phase (Group B). ${ }^{a}$

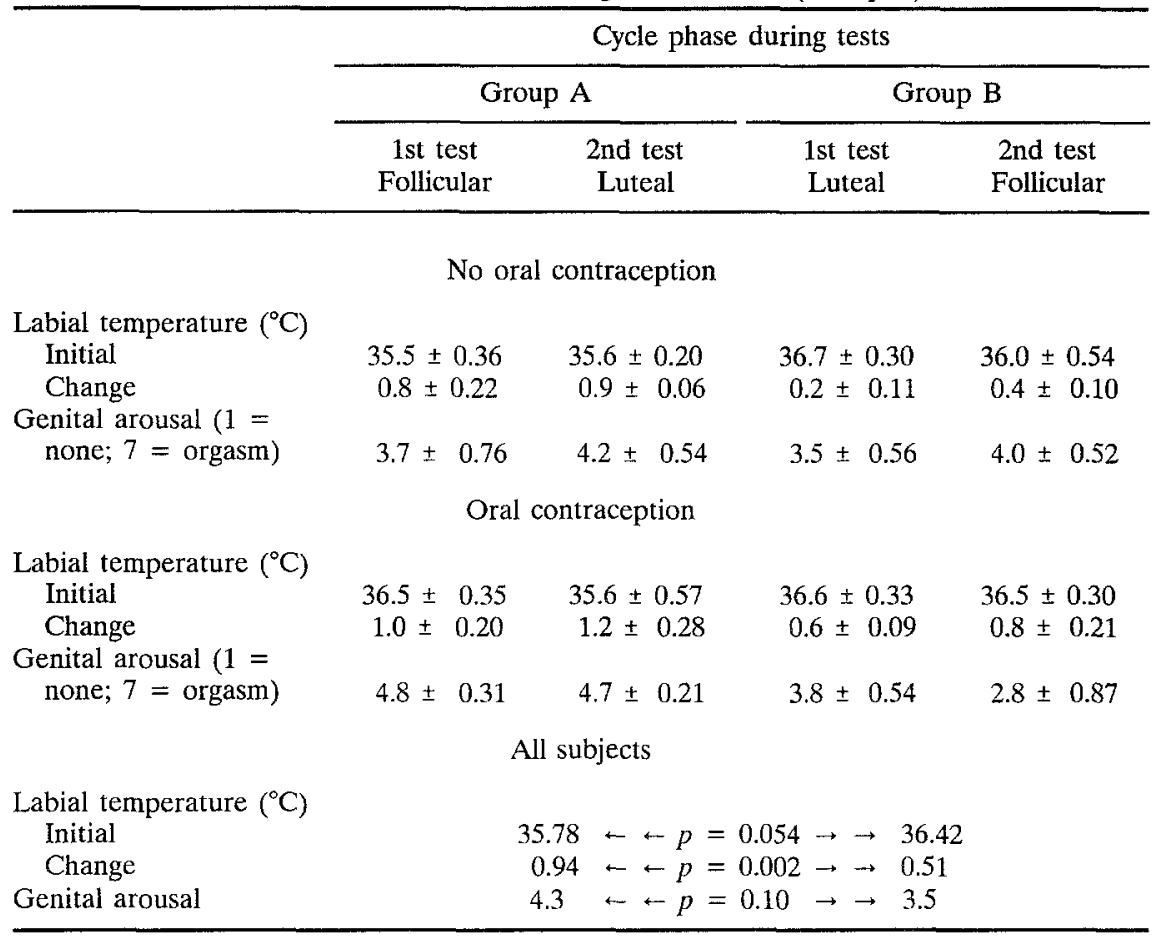

${ }^{a}$ Means \pm SE and $p$ values, 3-way ANOVA.

Again a significant overall difference, $F(1,20)=4.85, p=0.04$, was found in labial temperature increase attributable to the use of oral contraception.

Sexual arousal as measured by increase in labial temperature turned out to be significantly higher in women who were first tested during their follicular phase (Group A, no OC: 0.8 ; with $\mathrm{OC}: 1.0^{\circ} \mathrm{C}$ ) compared with women who were first tested during their luteal phase (Group B, no OC: 0.2 ; with OC: $0.6^{\circ} \mathrm{C}$ ). This was true for both categories of women, with and without OC. This difference between Groups A and B persisted when they were tested for the second time (Group A, no OC: 0.9 , with $\mathrm{OC}: 1.2^{\circ} \mathrm{C}$; Group B, no OC: 0.4 , with $\mathrm{OC}: 0.8^{\circ} \mathrm{C}$ ). Since there were no statistically significant overall differences in cycle phase, $F(1,20)=0.00$, ns, or significant interactions $F(1,20) \leq 2.18$, ns, follicular and luteal data were combined. It appeared that women of Group A showed a much higher objective sexual arousal than women of Group $\mathrm{B}, 0.94^{\circ} \mathrm{C}$, vs. $0.51^{\circ} \mathrm{C}, F(1,20)=12.68$, $p=0.002$. 
For initial labial temperature the only statistically significant difference was found between women of Group A $\left(35.78^{\circ} \mathrm{C}\right)$ and Group B $\left(36.42^{\circ} \mathrm{C}\right), F(1,20)=4.19, p=0.054$. There were no effects of cycle phase and oral contraception, or significant interactions.

For subjective genital arousal women of Group A scored somewhat higher than women of Group B, 4.3 vs. $3.5, F(1,20)=2.97, \mathrm{p}=0.10$.

ANOVA yielded no significant effects with respect to moods, testosterone levels, general sexual arousal, and postfilm feelings.

During the $24 \mathrm{hr}$ following the first experimental session, there was an increase in sexual appetite (i.e., desire for making love) in 6 of 12 women who had been tested during their follicular phase and in 1 of 12 tested during their luteal phase, $z=2.247, p<0.05$. Of those women that had made love, the initiative to do so had been taken by 5 of 8 women tested in their follicular phase and in 1 of 11 women tested in their luteal phase, $z=2.473, p<0.05$.

\section{DISCUSSION}

Women tested for the first time in their follicular phase were sexually more aroused by erotic video than women tested for the first time during their luteal phase. This was true for both objective (i.e., a labium minus change in temperature) and subjective genital arousal. When these women were retested in their alternative phase of the menstrual cycle those who were then follicular did not score higher than those who were then in their luteal phase. On the contrary, the latter group scored as high again as when tested during their follicular phase. This phenomenon was observed both in women with and without oral contraception. The nature of the menstrual phase, i.e., natural or pill-induced, seems irrelevant in this respect.

The sexual arousal achieved in the laboratory setting during the first session appeared to be correlated with an increase in their desire for making love later in the day when they were at home. Only 1 of 12 women tested during their luteal phase indicated an increase in desire to make love, while 6 of 12 women tested during their follicular phase indicated an increase in desire.

Apparently the menstrual cycle phase during the first test determines the immediate response, and indirectly affects the response during the second test approximately 11 days later. In a random block design the difference in sexual response between follicular and luteal phase of the menstrual cycle disappears (as seen by inspection of Table II).

The lack of an effect of the menstrual cycle phase on physiological sexual arousability in other studies (Morrell et al., 1984; Hoon et al, 1982) 
may be attributable to the methodology of design and analysis employed. Morrell et al. (1984) used vaginal photoplethysmography to measure changes in pulse amplitude in response to erotic film and fantasy and found no differences between the follicular, ovulatory, and luteal phases. They suggested that the order of testing was uniform, which might in light of the present findings explain why they did not find significant fluctuations. Hoon et al. (1982), using vaginal photoplethysmography and labium minus temperature to measure sexual arousal in response to erotic audio tapes and fantasy, found no differences between five phases of the menstrual cycle. The subjects began the experiment at random times in their cycle. The authors reported "no bias favoring any menstrual cycle assessment sequence" (p. 24). The scant data supplied, however, are inconclusive. Also, they do not refer to their earlier study (Wincze et al., 1976) in which a significant correlation (.64) was reported between vaginal blood volume and the day of the subject's menstrual cycle.

In another study (Schreiner-Engel et al., 1981), also using vaginal photoplethysmography and fantasy and erotic audiotape stimuli, lower physiological arousal was found during the ovulation phase compared to follicular and luteal phases. The latter two did not differ. Ten subjects entered the study in each of the three phases studied, but a possible effect of the phase at first testing, as found in the present study, was not analyzed. This is interesting in view of their statement made in another report on the same study: "Although women differed greatly from one another in arousability, each responded with a high degree of individual consistency on all measures regardless of stimulus condition or menstrual cycle phase" (Schreiner-Engel, et al., 1981, p. 263). One of the main findings of the present study indicates that the cycle phase at first testing is an important factor responsible for individual consistency over repeated tests.

In the present study women using oral contraception differed in a few respects from women not using the pill: In the follicular phase they had a higher initial labial temperature and in both phases they had a higher increase in labial temperature during erotic video. All OC women used pills with low estrogen plus a progestational agent. This progestational agent may have caused the labial temperature to be higher during the follicular phase. The greater increment in labial temperature during watching the erotic video in pill users is not understood. Possible contributing factors could be a direct effect of exogenous steroids on the genitalia and the greater sexual activity of the pill users.

\section{ACKNOWLEDGMENTS}

Thanks are due to Dr. F. H. de Jong for supervising the steroid hor- 
mone assays, Cor Geilman, Central Research Department Erasmus University Rotterdam for his continuous technical support in the course of this study, and to Dr. D. L. Rowland for his statistical advice and support. The cooperation of all the women subjects is gratefully acknowledged.

\section{REFERENCES}

Bancroft, J. (1989). Human Sexuality and Its Problems, Churchill Livingstone, Edingburgh, Scotland.

Beach F. A. (1948). Hormones and Behavior, Cooper Square, New York.

de Jong, F. H., Baird, D. T., and van der Molen, H. J. (1974). Ovarian secretion rates of oestrogens, androgens and progesterone in normal women and in women with persistent ovarian follicles. Acta Endocrinol. 77: 575-587.

Hatch, J. P. (1979). Vaginal photoplethysmography: Methodological considerations. Arch. Sex. Behav. 8: 357-374.

Henson, D. E., Rubin, H. B., Henson, C., and Williams, J, R. (1977). Temperature change of the labia minora as an objective measure of female eroticism. J. Behav. Ther. Exp. Psychiat. 8: 401-410.

Henson, D. E., Rubin, H. B, and Henson, C. (1982). Labial and vaginal blood volume responses to visual and tactile stimuli. Arch. Sex. Behav. 11: 23-31.

Hoon, P. W., Bruce, K., and Kinchloe, B. (1982). Does the menstrual cycle play a role in sexual arousal? Psychophysiology 19: 21-27.

Leshner, A. I. (1978). An Introduction to Behavioral Endocrinology, Oxford University Press, New York.

Morrell, M. J., Dixen, J. M., Carter, C. S., and Davidson, J. M. (1984). The influence of age and cycling status on sexual arousability in women. Am. J. Obstel. Gyncol. 148: 66-71.

Morris, N. M., and Udry, J. R. (1982). Epidemiological patterns of sexual behavior in the menstrual cycle. In Friedman, R. C. (ed.), Behavior and the Menstrual Cycle, Debber, New York.

Nieuwenhuijsen, K., de Neef, K. J., and Slob, A. K. (1986). Sexual behavior during ovarian cycles, pregnancy and lactation in group-living stumptail macaques (Macaca arctoides). Hum. Reprod. 1: 159-169.

Sanders, D., Warner, P., Bäckström, T., and Bancroft, J. (1983). Mood, sexuality, hormones and the menstrual cycle. I. Changes in mood and physical state: Description of subjects and method. Psychosom. Med. 45: 487-501.

Schreiner-Engel, P., Schiavi, R. S., and Smith, H. (1981). Female sexual arousal: relation between cognitive and genital assessments. J. Sex Marital Ther. 7: 256-267.

Schreiner-Engel, P., Schiavi, R. C., Smith, H., and White, D. (1981). Sexual arousability and the menstrual cycle. Psychosom. Med. 43: 199-214.

Slob, A. K., Koster, J., Radder, J. K., and van der Werff ten Bosch, J. J. (1990). Sexuality and psychophysiological functioning in women with diabetes mellitus. $J$. Sex Marital Ther. 16: $59-69$.

Verjans, H. L., Cooke, B. A., de Jong, F. H., de Jong, C. M. M., and van der Molen, H. J. (1973). Evaluation of a radioimmunoassay for testosterone estimation. J. Steroid. Biochem. 4: $665-676$.

Wincze, J. P., Hoon, E. F., and Hoon, P. W. (1976). Physiological responsivity of normal and sexually dysfunctional women during erotic stimulus exposure. J. Psychosom. Res. 20: 445451. 